\title{
Using social media effectively in a surgical practice
}

\author{
Mara B. Antonoff, MD \\ From the Department of Thoracic \& Cardiovascular Surgery, University of Texas MD Anderson Cancer Center, \\ Houston, Tex. \\ Disclosures: Author has nothing to disclose with regard to commercial support. \\ Received for publication June 30, 2015; revisions received Sept 27, 2015; accepted for publication Oct 11, 2015; \\ available ahead of print Nov 11, 2015. \\ Address for reprints: Mara B. Antonoff, MD, Department of Thoracic \& Cardiovascular Surgery, University of Texas \\ MD Cancer Center, 1400 Pressler St, Unit 1489, Houston, TX 77030 (E-mail: mbantonoff@mdanderson.org). \\ J Thorac Cardiovasc Surg 2016;151:322-6 \\ $0022-5223 / \$ 36.00$ \\ Copyright (C) 2016 by The American Association for Thoracic Surgery \\ http://dx.doi.org/10.1016/j.jtcvs.2015.10.016
}

About 5 years ago I passed a surgical intensive care unit room and saw an intern gathering what appeared to be supplies for a bedside procedure. I asked her if she needed any help, and she said that she was about to place a central line, and that she'd appreciate my supervision. Of course, I obliged, and I asked her how many central lines she'd previously placed. "Zero, unless you count the simulation lab." "No, problem," I said, "We will make sure that your first is successful. Have you seen any before?" Her confident response: "Absolutely. I've seen several, and 1 was just today." So I explained to her some of my own idiosyncrasies and tricks that I'd picked up over time, and I watched carefully as she positioned the patient perfectly, employed meticulous sterile technique, identified exact anatomic landmarks, found the subclavian vein on her first attempt, used Seldinger technique to place a triple-lumen catheter, and secured it in place after aspirating and flushing all ports appropriately. As I offered her praise for a job well done and reminded her to order a chest x-ray, I asked her, out of curiosity, which residents she'd observed placing lines in the past. "Oh, I've never observed any central lines placed here," she said. Before I could question her any further, she clarified, "I'm sorry-I didn't realize you were asking how many I'd seen performed here. I saw them all on YouTube." And with that comment, I realized that, over the course of my career, social media would be shaping medicine in ways beyond anything I'd ever imagined.

It is estimated that over $40 \%$ of adults carry a smartphone, with only a quarter of their telephone use time spent actually making calls. ${ }^{1,2}$ The remainder of their telephone time is consumed while exploring the Internet, interacting socially, and utilizing a variety of mobile-based applications, with the average user in the United States logging more than 37 hours per month. ${ }^{3}$ While the amount of time spent on these electronic devices is alarming, what is even more astounding is the extent to which mobile device use has helped spur an explosion in social media engagement. Social media has been defined as any form of electronic tinues to grow. ${ }^{6}$

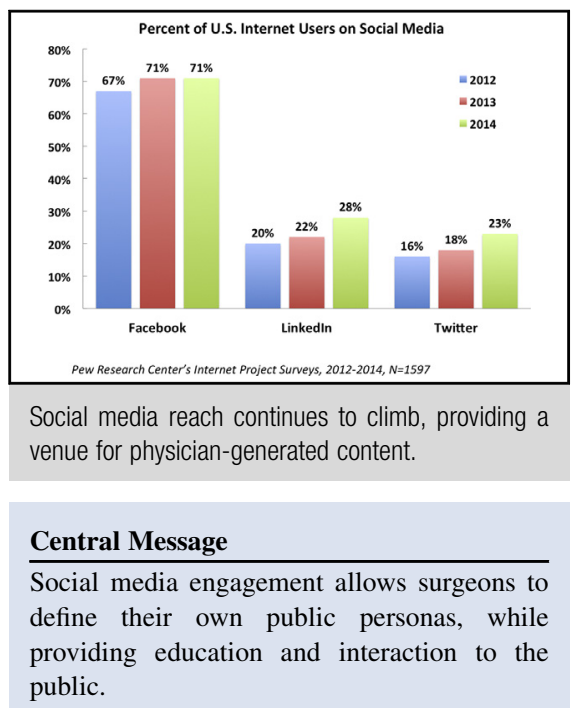

See Editorial Commentary page 326.

communication through which users create online communities to share information, ideas, personal messages, and other content. More than 1.5 billion people are registered users of social media networks, with greater than $80 \%$ engaging in regular use of these avenues of communication. ${ }^{4}$ In 2012, Facebook (Facebook, Inc, Menlo Park, Calif) surpassed 900 million active users, reporting continued staggering rates of user growth, and went public with an initial public offering of more than $\$ 16$ billion. ${ }^{5,6}$ As of March 2015, Facebook remains the most heavily used worldwide social media network, with 1.4 billion registered users. ${ }^{7}$ At over 300 million strong, Twitter contributors produce more than 500 million tweets per day, $80 \%$ of which are generated from mobile devices. ${ }^{8}$ LinkedIn (Mountain View, Calif), a social media site geared toward professionals, has over 77 million users, and con-

While social media use has exploded globally, exploitation of its potential benefits by medical professionals, and surgeons in particular, has been relatively delayed compared with the experiences of other vocations. ${ }^{6}$ Quite appropriately, physicians and medical practices have been cautious, reluctant to engage in casual interactions, oversharing of inappropriate information, and the public presentation of any image that would defray from the respect of our patients and colleagues. ${ }^{9}$ Apprehensive about potential vulnerability, surgeons have thoughtfully considered the effects of their online content, focusing on prevention of violations of patient privacy and avoidance of 
unprofessional public content that may reflect poorly on the entire field of practice. ${ }^{10}$ Social media is still felt to be underutilized in the health care domain, with widespread (although dissipating) skepticism and mistrust regarding the usefulness of social media in health care. ${ }^{11}$ However, as physicians first began to engage in carefully restrained engagement in social media for personal and social purposes, familiarity has been gained. A recent survey of Australian physicians revealed that $75 \%$ participated in social media, with the majority reporting active use at least once per week. ${ }^{9}$ Further, as leaders in health care social media have gradually educated us regarding the potential benefits that may be afforded to our practices, to our scholarly activity, and to the public whom we serve, interest in social media utilization has finally reached what some consider to be a critical tipping point. ${ }^{12,13}$ Not only has the proportion of surgeons participating in social media increased, a shift has occurred in the types of social media interaction taking place, with rapid growth in the use of social media for professional purposes.

One of the pivotal factors leading to heightened social media engagement by surgeons has been the realization that, due to our career choice, we all have public profiles easily searchable on the Internet. Don't believe it? Go to the Web-based search engine of your choice, and type your own name followed by "MD." If you're lucky, one of the first pages that comes up will be your profile via your institutional Web site or your CTSNet profile. You may find links to PubMed citations, or even an article touting your accomplishments. However, regardless of your clinical prominence and academic prestige, it is almost certain that your search results will include listings from U.S. News \& World Reports, Vitals.com, Healthgrades.com, and the like. Sites such as these, in which patients provide rankings and commentary, are highly prevalent. Even more frightening, much of the information on these sites comes from unverified, questionable resources, which are hardly a fair representation of ourselves. As you have witnessed in many of your new patient clinic visits, prospective patients come in to your office having searched the Web for information regarding their condition and possible treatment options. But they're not just looking up their disease process; they are looking you up, too. A recent study suggested that more than a quarter of patients in a surgical practice had specifically used physician rating Web sites in order to select their surgeons. ${ }^{14}$ While there is nothing that you can do (aside from providing outstanding care $100 \%$ of the time) to alter your appearance on physician rating Web sites, there is a world of opportunity in terms of creating your public persona and molding the way in which you are seen by the public. Further, you can not only optimize your own online profile, you can harness the opportunities afforded by social media to build your practice, promote your institution, herald the scientific and clinical achievements of our discipline, improve interactions with other physicians and advocacy groups, and educate the public.

Among the most frequently touted benefits of social media use by physicians are the opportunities to communicate with prospective patients, advocacy groups, and philanthropists. If consumers as a whole are using these forums to garner information, this is certainly an effective way to reach them. Further, by the sheer nature of the way that Twitter works, if one carefully curates an effectively extensive network, the downstream attention from a single tweet can be exponential. By sharing details of procedures performed at our institutions and the cuttingedge research in which we participate, we can build our own online reputations, gaining esteem for ourselves and the practices, which we represent. In addition, we have the opportunity to educate the public, providing key information from experts. Certainly, there is an abundance of material generated from nonexperts that is readily accessible for public consumption. Anything that we can do to dilute the false information by providing accurate, timely, and appropriate insight will function as an important public service.

Moreover, our potential to deliver educational material extends well beyond serving the public. Curricular opportunities provided via social media venues are unbelievably expansive, as evidenced by my encounter with the surgical intern taking her "see one" component of the "see one, do one, teach one" algorithm from YouTube. This site is filled with a multitude of surgical techniques, readily accessible at the click of a mouse, and previous reports have suggested regular viewing of such videos by resident physicians, fellows, and even attending surgeons looking to brush up before a case. ${ }^{6}$

Further, social media has served a unique place in addressing problem-based learning and improvement, one of the Accreditation Council for Graduate Medical Education's core competencies. Social media has a very clear and distinct role in scholarly activity, which has been shown successfully time and again in the world of surgery. An excellent example is seen in International General Surgery Journal Club, a Twitter-based organization providing monthly online discussions of new articles relevant to the practice of general surgery. This group has been particularly successful at engaging participants in timely discussions of relevance to health care practitioners and expanding the potential readership for the journals utilized. Other surgical specialties have similarly touted the success of employing social media for scholarly discussion. ${ }^{15,16} \mathrm{~A}$ recent endeavor has been initiated in the realm of cardiothoracic surgery, with the creation of the Thoracic Surgery Social Media Network (TSSMN), a collaborative effort from the Annals of Thoracic Surgery and the Journal of Thoracic and Cardiovascular Surgery. ${ }^{17}$ This group, consisting of active surgeons and social media delegates from adult 
cardiac, congenital cardiac, and general thoracic surgery, specifically aims to bring social media attention to key publications from both journals and to highlight ongoing accomplishments in our specialty. ${ }^{17}$

There are currently a number of cardiothoracic surgeons utilizing social media in breadth of ways, promoting our collective image for the benefit of our entire specialty. Certainly, for some, it is sporadic and oftentimes more situational. When you travel to major societal meetings, the occasional Tweeters come out of the woodwork, providing minute-to-minute updates regarding meeting events labeled with hashtags such as \#AATS2015 and \#STS2015. ${ }^{18}$ Among our community of surgeons, you will also find at least a dozen outstanding models of how to successfully apply the power of social media to our goals as surgeons and public service agents. Case in point: Dr David Tom Cooke of the University of California, Davis, Medical Center (Twitter handle @UCD_ChestHealth). Active in social media since 2012 and serving as a cofounder of Lung Cancer Social Media (\#LCSM) in 2013, Dr Cooke has collaborated with a breadth of individuals to develop this enormously fruitful endeavor, including lung cancer patients, caregivers, family members, advocates, health care providers, researchers, and nonprofit organizations. With regularly scheduled live tweet chats, \#LCSM's goals include providing education, developing public support, ending societal stigmata, and facilitating treatment for patients with lung cancer. Along with his LCSM cofounders, Dr Cooke has created a patient-centered forum for stakeholders in the lung cancer community, a virtual environment prime for generating innovative ideas to optimize patient outcomes. Boasting nearly 1500 Twitter followers and almost 5000 tweets, Dr Cooke provides an enormous service to the LCSM community, as well as to his social media following at large. In another unique, novel approach to employing social media to bring valuable content to lay people, Cooke orchestrated a live-tweet chat held in conjunction with an operative procedure in March of 2015. Armed with the idea for over a year prior to the operation, the team went to great lengths to ensure all appropriate approvals were in place and to select the best patient candidate. Once the plans were laid, Dr Cooke performed a video-assisted right lower lobectomy on the patient while the tweet team from the University of California, Davis, shared informational elements related to the procedure along with caveats of preoperative planning and postoperative recovery. Selected video clips of portions of the procedure were shared in a delayed fashion, in compliance with established policies on live surgical broadcasts. Prepared educational multimedia videos, photographs, and links were broadcasted to followers throughout the day of the operation. With such outstanding ideas-and the passion, drive, and energy to make it work-Cooke serves as an exceptional role model for those of us interested in using social media to broaden our scope of public service.

When asked his rationale for participating in social media, Dr Cooke reports that he believes in "defining your own narrative." Consistent with the assertions put forth by other social media health care leaders, he contends that "being active in social media helps control how you are perceived online and on the Internet." He further explains, "Internet searches are directed toward the most active content. So being participatory in social media directs searches to positive professional content." Cooke also notes that, as physicians, we have much to gain from hearing the voices of other participants in social media, stating that "being active in disease-specific social media enables the clinician to learn from a patient-centered perspective."

Despite the ever-growing numbers of success stories and the clear advantages of social media utilization persistent concerns regarding its use have been described by investigators examining online engagement of health care professionals. A 2014 survey-based study of physician social media use categorized the most common challenges experienced by doctors into 6 dominant categories. ${ }^{11}$ These included apprehension regarding maintenance of confidentiality, lack of active participation, lack of trust, difficulty finding adequate time, workplace acceptance and support, and information anarchy. Such concerns are certainly valid and merit appropriate consideration. However, recommendations for best practices have been suggested by physician leaders in the social media realm, many of which address these sources of trepidation. ${ }^{11,19}$

Tips for effective social media use:

- Create your own personal identity. This is your opportunity to define for the public how you want to be viewed, for what you would like to be known. Consider your clinical and research interests, and make posts that jive with who you are. Whether your posts focus on novel techniques for endoscopic mucosal resection, public advocacy for the international community of patients with congenital heart defects, or the latest research in myocardial ischemia, this is your chance to cultivate the results that ensue when consumers type your name into their Internet search engines. As you create your own identity, be clear that that thoughts and views expressed are your own, and not those of your hospital or institution.

- Separate your personal from professional life. I'm not saying that you must avoid connecting with family and friends on social media-just find a way to separate your professional persona so that you maintain the public appearance that you desire. One approach utilized by a number of surgeons is to establish professional accounts through Twitter and LinkedIn, while maintaining a more personal account through Facebook. With the ability to activate more stringent privacy settings, Facebook is a 
great place to share photographs of your kids' graduation ceremonies with cousins across the country. All tweets are publicly searchable, and, for this reason, should really only include content meant for the masses.

- Be aware of institutional policies. It is more than likely that your employer already has a social media policy in place, and it behooves you to make yourself aware of pertinent guidelines. These policies tend to include smart and safe practices, including protection of private health information, preservation of professional boundaries, and appropriate use of trademarks. If you find that, by chance, your employer does not have a policy in place, check out the guidelines created by the American Medical Association and published online in $2010 .^{20}$

- Be thoughtful, take your time, and understand your audience. Dr Cooke suggests that new users "lurk" in a new medium before becoming active participants. He explains, "for example, when I opened my Twitter account, I spent 3 months on Twitter just observing the conversations before sending out a Tweet. This conservativeness allowed me to understand the subtle nuances of Twitter, and to identify the major players who drove the conversation about lung cancer and other aspects of surgery and health care."

- Use your network to grow your network. Select those whom you follow thoughtfully, not only based on their interests and objectives, but also based on those with whom they are connected. When you make posts, tag key stakeholders who have large followings, increasing your visibility. Further enhance your visibility by using hashtags, considering the use of tools to schedule or automate tweets, and retweeting the content of influencers with an accompanying mention. Join in on tweet chats or start your own.

- Engage your audience with interesting and eye-catching content. Social media feeds do not function like an e-mail inbox; you need to keep your followers involved by providing content that they find attractive and valuable. There are ample data showing that posts containing photographs, videos, and Web links get much more attention than simple text content.

- Recognize the permanence of your online activity. Cautions Cooke, "Always remember that social media is an 'instant press conference.' Whatever you say on social media cannot be taken back, or scrubbed from the Internet. Be careful of what you say, and think 3 times before posting anything."

- Serve as a positive social media role model for trainees. In the world of social media, a simple act such as issuing a friend request across professional boundaries can be interpreted as an ethical violation. ${ }^{21}$ Moreover, it has been well documented that medical students and resident physicians are commonly involved in unprofessional online conduct, with minimal privacy settings to protect their outward images. ${ }^{22}$ Nonetheless, as we are all coming to learn, social media offers tremendous potential for recruiting, communication, and education. ${ }^{21}$ By example, we must teach our trainees to optimize potential benefits while minimizing risks (even if we need to ask the trainees for technical help along the way).

For those still reluctant to embark on a journey into the world of social media, recognize that this is just another form of communication. The ways that we communicate with our peers, our patients, and our community as a whole continue to evolve. Handwritten letters have been replaced (when appropriate) with e-mails. Text messages have rendered voicemail boxes neglected and void of attention. Paying to print copies of photographs for friends and family members has become completely unnecessary, as we can now share our memories via E-mail, text message, and social media venues. In the past, if you read a journal article with which you disagreed or felt particularly compelled to express your opinion, your options were to write a letter to the editor for possible consideration of eventual publication or to wait until the next societal meeting to hash it out. The opportunity to share your thoughts in real time with your peers is here now, and listeners are waiting to hear your voice. Your discoveries don't need to wait, nor do your ideas, recommendations, or difficult questions. Patients are out there, eager to be educated and ready to click on your links. Your colleagues are waiting for your comments with anticipation, prepared to pounce on your bad ideas, retweet the good ones, and collaborate on future projects. Philanthropists and former patients, surgeons of the future, and researchers with wisdom of the past-they are all out there, waiting, and excited to learn how you will choose to define yourself.

\section{References}

1. Harvard Business Review Staff. How people really use mobile. Harv Bus Rev. 2013.

2. Vohra RS, Hallissey MT. Social networks, social media, and innovating surgical education. JAMA Surg. 2015;150:192-3.

3. The Nielsen Company. So many apps, so much more time for entertainment Available at: http://www.nielsen.com/us/en/insights/news/2015/so-many-appsso-much-more-time-for-entertainment.html. Accessed June 29, 2015.

4. Chui M, Manyika J, Bughin J, Dobbs R, Roxburgh C, Sarrazin H, et al. The social economy: unlocking value and productivity through social technologies. London: McKinsey Global Institute; 2012.

5. Goldman D. Facebook tops 900 million users. Available at: http://money.cnn com/2012/04/23/technology/facebook-q1/. Accessed June 29, 2015.

6. Margolin D. Social media and the surgeon. Clin Colon Rectal Surg. 2013;26: 36-8.

7. The Statistics Portal. Leading social networks worldwide as of March 2015, ranked by number of active users. March 2015. Available at: http://www.statista.com/ statistics/272014/global-social-networks-ranked-by-number-of-users/. Accessed June 29, 2015.

8. Twitter usage: company facts. March 31, 2015. Available at: https://about.twitter. com/company. Accessed June 29, 2015.

9. Brown J, Ryan C, Harris A. how doctors view and use social media: a national survey. J Med Internet Res. 2014;16:e267.

10. Greysen SR, Kind T, Chretien KC. Online professionalism and the mirror of social media. J Gen Intern Med. 2010;25:1227-9. 
11. Panahi S, Watson J, Partridge H. Social media and physicians: exploring the benefits and challenges. Health Inform J. July 18, 2014 [Epub ahead of print].

12. Cooper CP, Gelb CA, Rim SH, Hawkins NA, Rodriguez JL, Polonec L. Physicians who use social media and other internet-based communication technologies. J Am Med Inform Assoc. 2012;19:960-4.

13. McGowan BS, Wasko M, Vartabedian BS, Miller RS, Freiherr DD, Abdolrasulnia M. Understanding the factors that influence the adoption and meaningful use of social media by physicians to share medical information. J Med Internet Res. 2012;14:e117.

14. Curry E, Li X, Nguyen J, Matzkin E. Prevalence of internet and social media usage in orthopedic surgery. Orthop Rev (Pavia). 2014;6:5483.

15. Roupret M, Misrai V. Exponential use of social media in medicine: example of the interest of Twitter in urology. Prog Urol. 2015;25:11-7.

16. Topf JM, Hiremath S. Social media, medicine and the modern journal club. Int Rev Psychiatry. 2015;27:147-54.
17. Antonoff MB. Thoracic Surgery Social Media Network: bringing thoracic surgery scholarship to Twitter. J Thorac Cardiovasc Surg. 2015;150:292-3.

18. Wilkinson SE, Basto MY, Perovic G, Lawrentschuk N, Murphy DG. The social media revolution is changing the conference experience: analytics and trends from eight international meetings. BJU Intl. 2015;115:839-46.

19. Vaughn C. 8 Social media tips for physicians. Healthcare Marketing Advisor. 2012; April.

20. American Medical Association's Opinion 9124: professionalism in the use of social media. Available at: http://www.ama-assn.org/ama/pub/physicianresources/medical-ethics/code-medical-ethics/opinion9124.page. Accessed June $30,2015$.

21. Pillow MT, Hopson L, Bond M, Cabrera D, Patterson L, Pearson D, et al. Social media guidelines and best practices: recommendations from the council of residency directors social media task force. West J Emerg Med. 2014;15:26-30.

22. Wells DM, Lehavot K, Isaac ML. Sounding off on social media: the ethics of patient storytelling in the modern era. Acad Med. 2015;90:1015-9.

\title{
EDITORIAL COMMIENTARY
}

\section{Using social media: A way for us to sit at the table}

\author{
Susan D. Moffatt-Bruce, MD, PhD, FACS, FRCSC
}

\footnotetext{
From the Division of Thoracic Surgery, Department of Surgery, The Ohio State University, Columbus, Ohio. Disclosures: Author has nothing to disclose with regard to commercial support.

Received for publication Oct 26, 2015; accepted for publication Oct 27, 2015; available ahead of print Nov 19, 2015.

Address for reprints: Susan D. Moffatt-Bruce, MD, PhD, FACS, FRCSC, Division of Thoracic Surgery, Department of Surgery, 410 W 10th Ave, Columbus, OH 43210 (E-mail: Susan.moffatt-bruce@osumc.edu).

J Thorac Cardiovasc Surg 2016;151:326-7

$0022-5223 / \$ 36.00$

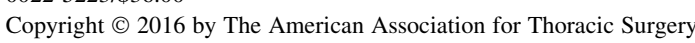

http://dx.doi.org/10.1016/j.jtcvs.2015.10.097
}

Social media in all of its different formats has become the surgeon's reality. In this issue of the Journal, Antonoff, ${ }^{1}$ as part of the invited Young Surgeon's Note series, has very nicely outlined that social media includes really any form of electronic communication through which users create online communities to share information, ideas, and personal messages, and she notes that more than 1.5 billion people are registered users of social media networks, with more than $80 \%$ engaging in regular use of these avenues of communication. I agree entirely with Antonoff ${ }^{1}$ when she elaborates on the fact that while the rest of the world, in many different industries, have embraced technology that has rendered the world a much smaller place, we surgeons have not been as quick to adapt. This lack of adaptation by us as surgeons has been paralleled by an increasing set of metrics by which we are measured and that are now publically reported on our behalf. ${ }^{2}$ The current paradigm surrounding the public reporting of surgical outcomes is evolving at a speed that is astounding, and this has left us as providers trying to manage the game of "shame and blame" so that the data are actually reflective of how we take care of our patients. Attempts to assess the quality

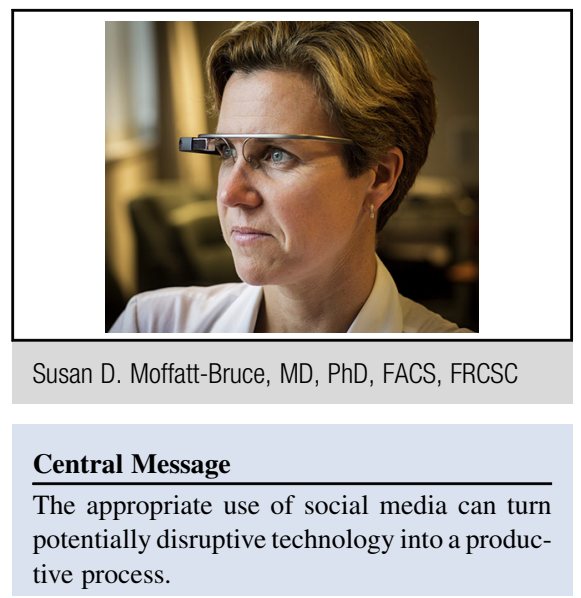

See Article page 322.

and safety of hospitals have proliferated-some might say that they have become a cottage industry - and they include a growing number of consumer-directed hospital rating systems. Relatively little is known about what these rating systems reveal, however, other than to confirm that there appear to be more than 700 top 100 hospitals in America! To further our understanding of differences in hospital ratings, Austin and colleagues ${ }^{3}$ recently published a comparison of 4 national rating systems, including U.S. News \& World Report's “Best Hospitals" report, Leapfrog, Centers for Medicare and Medicaid Services' (CMS's) Hospital Compare, Consumer Reports and Healthgrades. They designated "high" and "low" performers for each rating 